\title{
Malignant neuroendocrine tumour in an adult female diagnosed with Currarino syndrome
}

\author{
E Coetzee, ${ }^{1}$ S Malaka ${ }^{2}$ \\ ${ }^{1}$ University of Cape Town, South Africa \\ ${ }^{2}$ PathCare Laboratory, South Africa
}

Corresponding author: Emile Coetzee (emile@rectalsurgery.co.za)

\begin{abstract}
Summary
Currarino syndrome is a rare, autosomal dominant condition of caudal anomalies, usually diagnosed in childhood. Adult presentation is rare and malignant transformation of the associated presacral mass even more so. We report a case of a 60-year-old female diagnosed with a malignant neuroendocrine tumour in the presacral mass in Currarino syndrome and describe the surgical management and pathological findings.
\end{abstract}

S Afr J Surg 2019;57(4)

http://dx.doi.org/10.17159/2078-5151/2019/v57n4a3145

\section{Case report}

A 60-year-old female was referred with intractable constipation and a megarectum. She gave a history of lifelong constipation. As an infant and toddler, she was treated at a tertiary paediatric hospital for "anal stenosis" and a bicornate uterus. She was also diagnosed with an abnormally located left kidney. Her parents managed her evacuatory problems

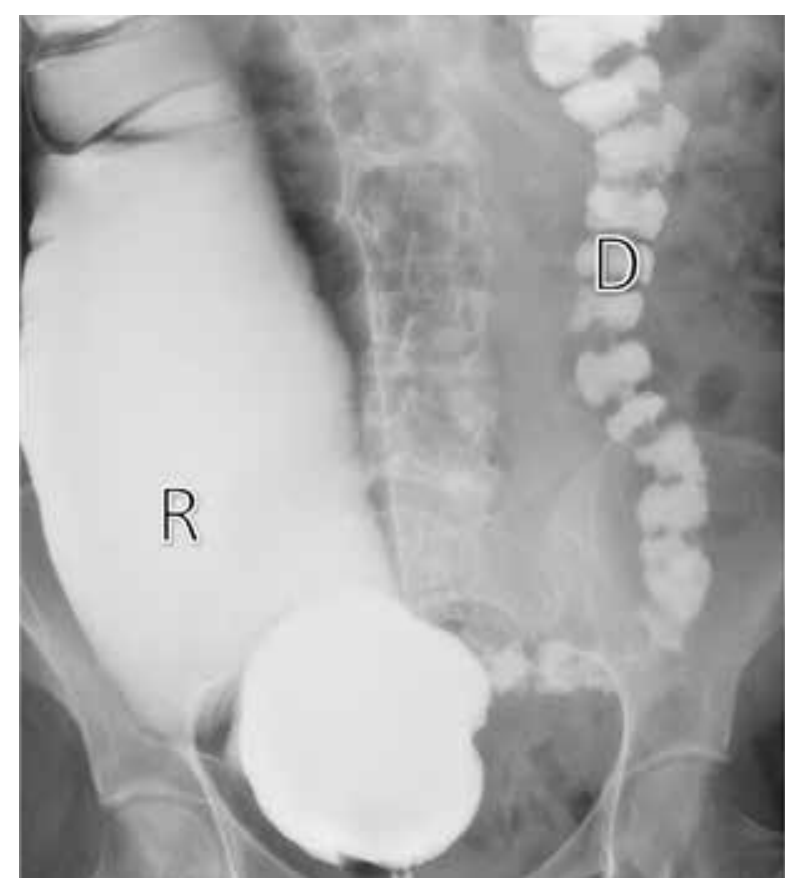

Figure 1. Barium enema and Coronal CT

D: Descending colon

$R$ : Abnormal, dilated rectum located to the right of the abdomen, extending to above the liver

$K$ : Left rotated, pelvic kidney with anal dilatation. Almost 60 years later, the notes of her treatment at that institution were not obtainable.

The reason for presentation was worsening abdominal pain, constipation, and pelvic discomfort. She has no comorbid diseases. Past abdominal surgical history, after the repair of the bicornate uterus, includes a laparotomy for ectopic pregnancy, two caesarean sections, and a hysterectomy.

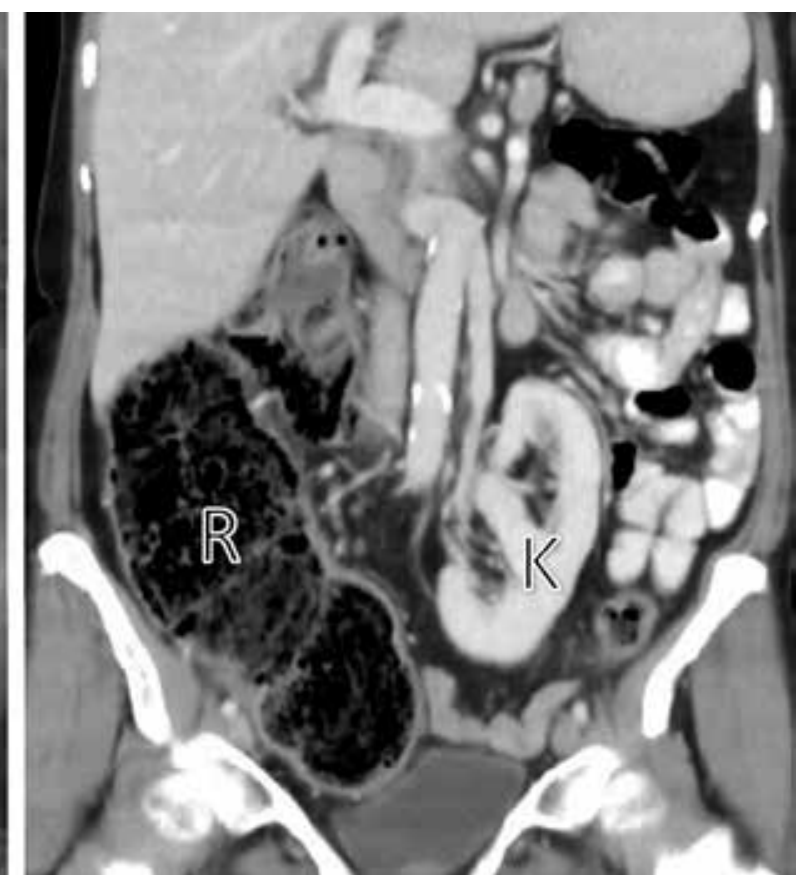




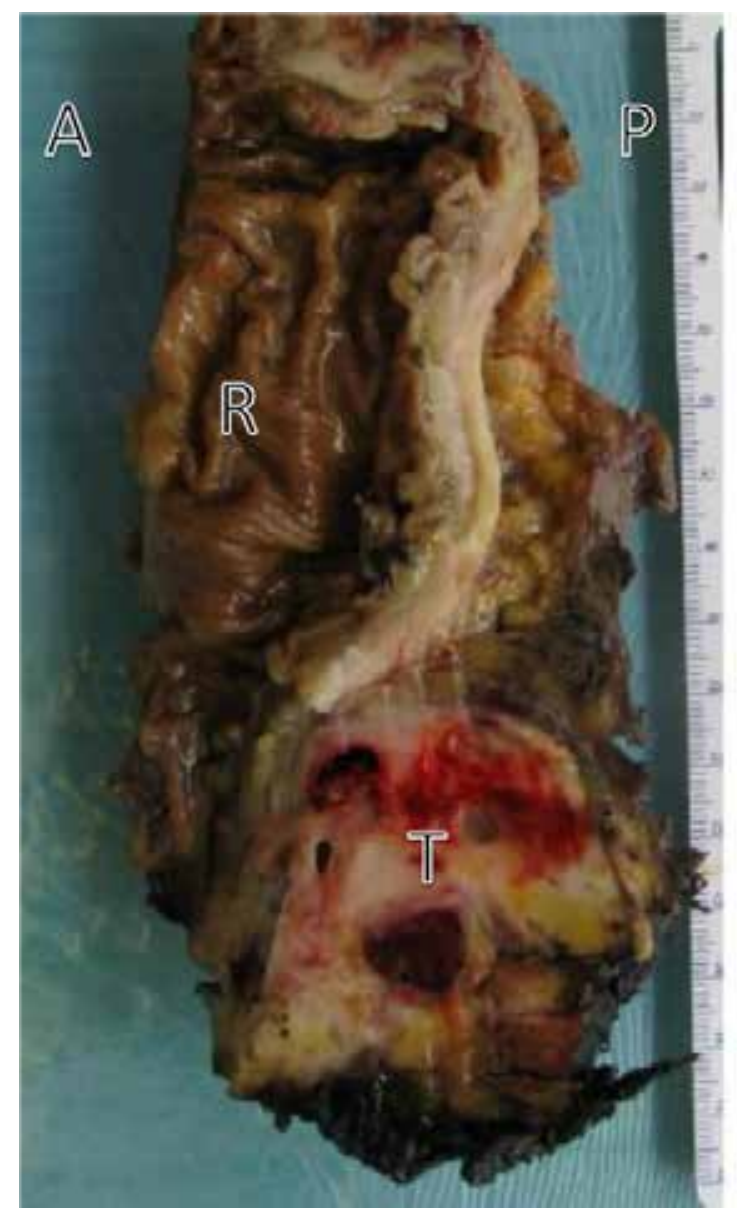

Figure 2. Macroscopic specimen and MRI

A: Anterior

P: Posterior

S: Sacrum

On examination, a large faecal mass was palpable in the abdomen. Vaginal examination was normal with a normal introitus and vaginal vault. Her anus was abnormally ovalshaped with the dentate line almost visible on the anal verge. She had normal anal sensation, normal anal wink, normal tone and adequate squeeze of the pelvic muscles. A wellcircumscribed, firm, solid-cystic, extra mucosal mass was palpable posterior to the rectum. It was approximately $8 \mathrm{~cm}$ $\mathrm{x} 5 \mathrm{~cm}$ in size.

Barium enema before referral showed a grossly abnormal distended rectum extending from the pelvic floor to the right upper quadrant above the liver. The proximal colon, from below the right hemidiaphragm, had a normal caliber and haustration (Figure 1).

CT scan of the abdomen showed the pelvic anomalies as described on the MRI, and demonstrated the abnormal configuration of the colon, a malrotated left pelvic kidney and a few uncomplicated biliary cysts (Figure1). There was no evidence of metastatic pathology in the chest or abdomen. Anorectal manometry confirmed an intact recto-anal inhibitory reflex (RAIR).

MRI of the pelvis demonstrated an anterior sacral meningocoele with spinal dysraphism and anterior osseous defect. It had a multiloculated cystic component of $3 \mathrm{~cm}$

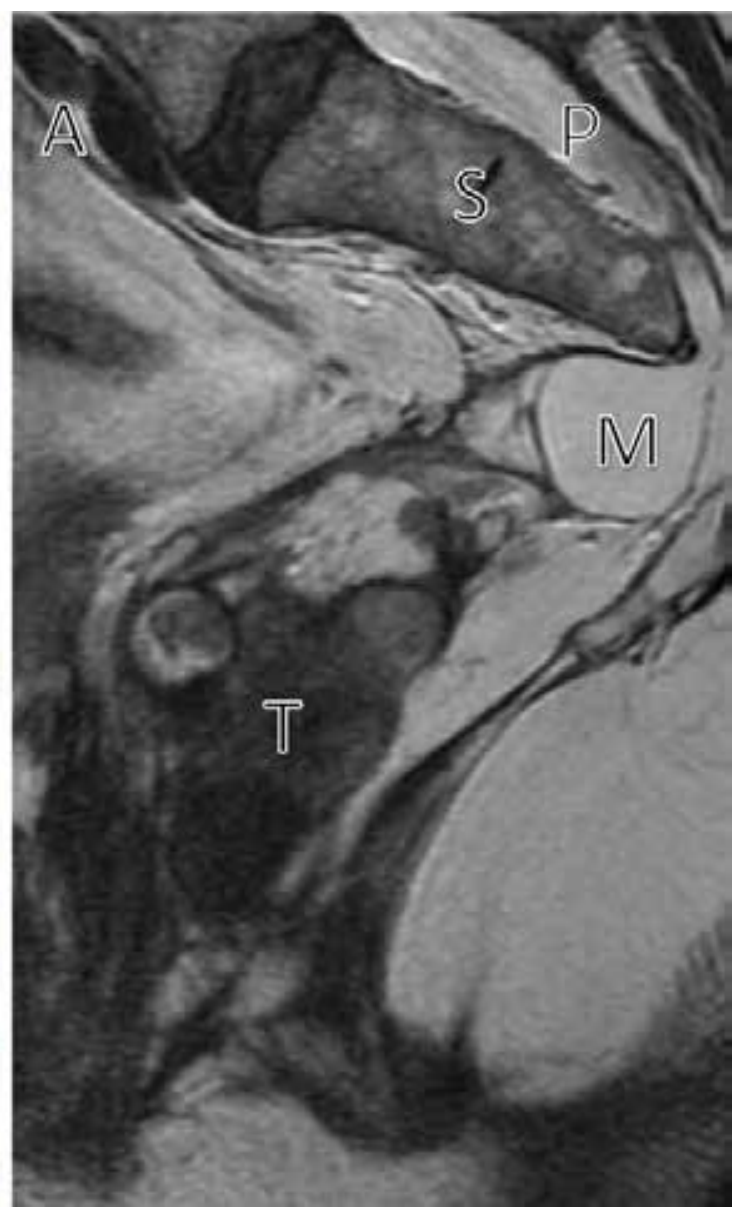

R: Rectum

M: Anterior meningocoele T: Teratoma

x $2 \mathrm{~cm} \mathrm{x} 3 \mathrm{~cm}$ in size. Inferior to this, a poorly defined multiloculated solid-cystic presacral mass, inseparable from the posterior wall of the rectum and closely related to the pelvic floor, was demonstrated (Figure 2).

Surgical treatment was approached in three stages. First, the meningocoele and sacral defect were repaired via a posterior approach. After the repair, she was repositioned in a supine position and a laparoscopic-assisted loop colostomy performed at the level of the transition of the caliber of the colon. This to address her severe symptoms of constipation and evacuatory dysfunction.

Six weeks later an anterior resection with resection of the presacral mass, coloanal anastomosis and covering ileostomy was done. The ileostomy was reversed 8 weeks after the second procedure. Following the anterior resection, she temporarily developed a neurogenic bladder managed with intermitted self-catheterisation. This completely resolved within six weeks following surgery.

A representative image of the specimen (Figure 2) confirmed a partially circumscribed tumour posterior to the rectum. The tumour was composed of a solid mass with small cysts and patchy areas of necrosis.

Histology of the tumour revealed a grade 2 neuroendocrine tumour (WHO/ENETS 2010), ${ }^{1}$ arising from a benign 

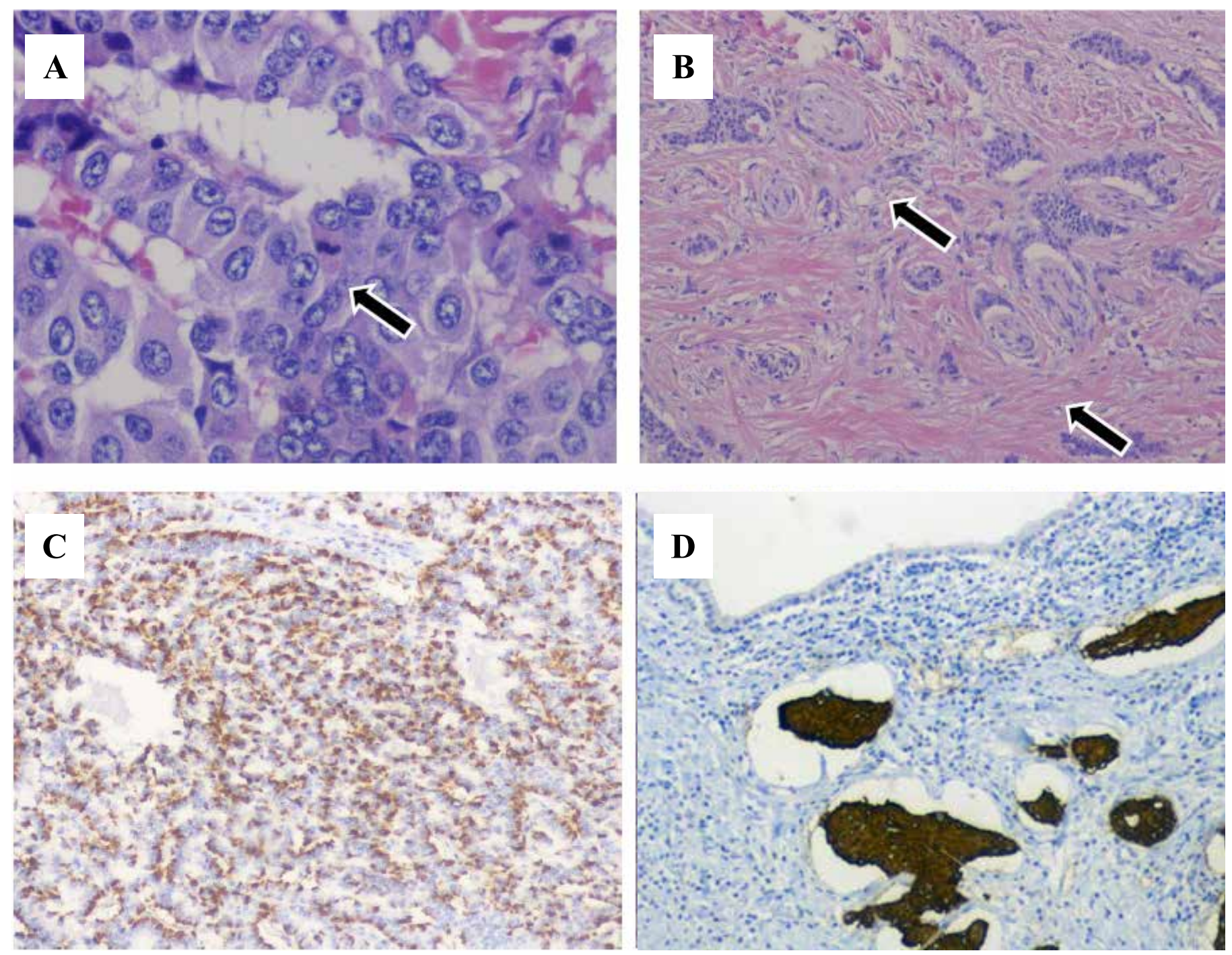

Figure 3. Histology

A: Trabecular growth pattern with one of the many mitotic figures (arrow).

B: Periphery of the tumour with areas of perineural invasion.

$C$ : Neuroendocrine differentiation as confirmed by synaptophysin positivity.

D: The background benign teratoma with mucous epithelial-lined cystic structure and surrounding mature glial tissue (GFAP).

teratoma. The neuroendocrine tumour had a cribriform and trabecular growth pattern with scattered mitotic figures, at most, 10 per 10 high power fields. The Ki67 index was $14 \%$. The neuroendocrine differentiation was confirmed by positive Chromogranin A and synaptophysin immunohistochemical stains. There was direct infiltration of the muscularis propria of the rectum. Perineural invasion was also demonstrated at the periphery of tumour. The tumour was completely excised with clear margins of at least $4 \mathrm{~mm}$. The background teratoma was composed of mature glial tissue, and glandular structures lined by respiratory and mucus-secreting cystically dilated glands. Some of the glands contained areas of metaplastic squamous epithelium. Glial tissue was highlighted on a GFAP immunohistochemical stain (Figure 3).

At 18-month follow-up, she is well, continent for both urine and faeces and has good bowel function and quality of life. She remains clear of malignant disease.

\section{Discussion}

Currarino syndrome (CS) is a rare congenital condition of caudal anomalies consisting of a triad of anorectal stenosis, sacral defect, and a presacral mass. It was first described by Currarino et al. in 1981. ${ }^{2}$ The syndrome is inherited in an autosomal dominant pattern as a result of mutations in the homeobox HLXB9 gene on chromosome 7 and genetic testing is available. ${ }^{3}$ There are various presentations and phenotypes, making diagnosis sometimes difficult. The presacral mass is an anterior sacral meningocoele in $60 \%$, a teratoma in $25 \%$ and other tumours in other patients. ${ }^{4}$ Currarino syndrome is mostly diagnosed in the paediatric population, but rarely adults present with complications of the anomalies. ${ }^{5-7}$

Malignant neuroendocrine differentiation of the presacral mass is rare, with only four publications reporting neuroendocrine differentiation of the presacral mass. ${ }^{5,8-10}$ In the reported cases, the diagnosis of CS was made at ages $19,{ }^{10}$ 
$22,{ }^{5} 30^{9}$ and $44 .{ }^{8}$ Diagnosis of CS as in this report at the age of 60 is not previously documented .

The main presenting symptom is constipation. This is due to the anal stenosis and usually results in the diagnosis being made during childhood. Although this patient had constipation and anal stenosis, she was treated at a tertiary paediatric institution from 1958 to 1960 , long before CS was described (1981). ${ }^{2}$ The diagnosis was therefore not made earlier.

Renal/urinary tract anomalies are frequently reported, with the incidence highly variable. Anomalies described include duplex ureter, horseshoe or duplex kidney, neurogenic bladder, vesicoureteric reflux, recurrent urinary tract infections, urinary incontinence, and secondary hydronephrosis. ${ }^{4}$ This patient had a malrotated left kidney located at the pelvic inlet.

Gynaecological abnormalities have been reported in 13$19 \%$ of female patients in other case series. ${ }^{4,10}$ These include bicornuate uterus, rectovaginal fistula, and septate vagina. This patient had a bicornate uterus and this anomaly was also described in 2 of the reported cases where a malignant neuroendocrine tumour was diagnosed.

Genetic counselling and testing should be offered to all families where the diagnosis has been made based on the phenotypic presentation. This patient has a sister and a daughter who had constipation, anal stenosis and evacuatory complaints. The diagnosis was subsequently made in both individuals.

Single-stage surgery is often used to treat patients with CS and rectal resection is seldom indicated. ${ }^{5,10}$ We elected for a staged approach as an intersphincteric coloanal anastomosis carries a high the risk of anastomotic complications. Septic anastomotic complications could have resulted in meningitis had the meningocoele been repaired during the same operation.

The histology revealed a well-differentiated NET arising from a benign teratoma, similar to those reported in other cases of malignant neuroendocrine tumours in Currarino syndrome. Complete surgical resection was achieved, and she has remained clear of disease at 18-month follow-up.

\section{Conclusion}

Currarino syndrome is rare and malignant transformation of the presacral mass even more so. First-degree relatives should be screened and treated to avoid morbidity of treatment, other complications of CS and malignant transformation of the presacral mass.

\section{Declarations}

The authors of this manuscript declare that:

Both authors have made substantial contributions to all of the following:

- The conception and design of the study.

- Drafting the article or revising it critically for important intellectual content.

- Final approval of the version to be submitted.

- Sound scientific research practice.
The authors further confirm that:

- The manuscript, including related data, figures and tables has not been previously published and is not under consideration elsewhere.

- No data have been fabricated or manipulated (including images) to support our conclusions.

- This submission does not represent a part of single study that has been split up into several parts to increase the quantity of submissions and submitted to various journals or to one journal over time (e.g. "salami-publishing").

Plagiarism:

- The authors confirm that the work submitted is original and does not transgress the plagiarism policy of the journal.

- No data, text, or theories by others are presented as if they were the authors' own.

- Proper acknowledgements of other's work have been given (this includes material that is closely copied, summarised and/or paraphrased), quotation marks are used for verbatim copying of material.

Funding sources

- No funding was obtained whatsoever.

Compliance with ethical guidelines

- The authors declare that this submission is in accordance with the principles laid down by the Responsible Research Publication Position Statements as developed at the 2nd World Conference on Research Integrity in Singapore, 2010.

\section{Ethics}

Written informed consent was obtained from the patient to write a case report.

\section{Orcid}

\section{E Coetzee http://orcid.org/0000-0001-7384-1386}

\section{REFERENCES:}

1. Bosman FT, Carneiro F, Hruban RH, et al. WHO classification of neuroendocrine tumours of the digestive system. The Digestive System, 4th ed. IARC Press; 2010.

2. Currarino G, Coln D, Votteler T. Triad of anorectal, sacral, and presacral anomalies. AJR Am J Roentgenol. 1981 Aug;137(2):395-8. Available from: https://doi.org/10.2214/ ajr.137.2.395

3. Belloni E, Martucciello G, Verderio D, Ponti E, Seri M, Jasonni $\mathrm{V}$, et al. Involvement of the HLXB9 homeobox gene in Currarino syndrome. Am J Hum Genet. 2000 Jan;66(1):312-9. Available from: https://doi.org/10.1086/302723

4. Kochling J, Karbasiyan M, Reis A. Spectrum of mutations and genotype-phenotype analysis in Currarino syndrome. Eur J Hum Genet. 2001 Aug;9(8):599-605. Available from: https:// doi.org/10.1038/sj.ejhg.5200683

5. Pendlimari R, Leonard D, Dozois EJ. Rare malignant neuroendocrine transformation of a presacral teratoma in patient with Currarino syndrome. Int J Colorectal Dis. 2010 Nov;25(11):1383-4. Available from: https://doi.org/10.1007/ s00384-010-0953-2 
6. Zia-ul-Miraj M, Brereton RJ. Currarino's triad: an unusual cause of constipation in children. Pediatr Surg Int. 1998 Jul;13(5-6):437-9. Available from: https://doi.org/10.1007/ s003830050362

7. Cretolle C, Zerah M, Jaubert F, Sarnacki S, Revillon Y, Lyonnet $\mathrm{S}$, et al. New clinical and therapeutic perspectives in Currarino syndrome (study of 29 cases). J Pediatr Surg. 2006 Jan;41(1):126-31;discussion 126-31. Available from: https:// doi.org/10.1016/j.jpedsurg.2005.10.053

8. Ciotti P, Mandich P, Bellone E, Ceppa P, Bovio M, Ameri P, et al. Currarino syndrome with pelvic neuroendocrine tumor diagnosed by post-mortem genetic analysis of tissue specimens.
Am J Med Genet A. 2011 Nov;155A(11):2750-3. Available from: https://doi.org/10.1002/ajmg.a.34031

9. Colombo F, Janous P, Buxton N. Carcinoid transformation of presacral dermoid cyst in patient with Currarino syndrome: a case report. Br J Neurosurg. 2017:1. Available from: https://doi. org/10.1080/02688697.2017.1339226

10. Urioste M, Garcia-Andrade Mdel C, Valle L, Robledo M, Gonzalez-Palacios F, Mendez R, et al. Malignant degeneration of presacral teratoma in the Currarino anomaly. Am J Med Genet A. 2004 Jul 30;128A(3):299-304. Available from: https:// doi.org/10.1002/ajmg.a.30028 